\title{
Pengaruh Dimensi Reservoir terhadap Flow Rate Pompa Infus Insulin
}

\author{
(The Effect of Reservoir Dimension on the Flow Rate of Insulin Infusion Pump) \\ Rahmad Kuncoro Adi ${ }^{a}$, Krisdiyanto ${ }^{b}$ \\ a,b Program Studi Teknik Mesin, Fakultas Teknik, Úniversitas Muhammadiyah Yogyakarta \\ Jl. Brawijaya, Kasihan, Bantul, Yogyakarta 55183 \\ e-mail: rahmadkuncoroadi@gmail.com, krisdiyanto@umy.ac.id
}

\begin{abstract}
Abstrak
Pompa infus insulin adalah peralatan medis semi otomatis yang digunakan untuk mengontrol tingkat gula darah penderita diabetes. Cara kerja perangkat tersebut yaitu dengan cara memasukkan insulin dari reservoir insulin kedalam tubuh pasien secara kontinu. Reservoir insulin merupakan tempat penyimpanan insulin sebelum dimasukkan ke dalam tubuh pasien. Komponen utama pompa infus insulin terdiri dari pompa, motor, reservoir, tube, dan microprocessor. Perangkat tersebut memasukkan insulin sesuai dengan flow rate yang telah diatur. Dimensi reservoir perlu dipertimbangkan agar flow rate yang keluar dari perangkat tersebut akurat. Simulasi pemberian kecepatan fluida pada reservoir insulin dapat dilakukan dengan perangkat lunak berbasis computational fluid dynamics. Kecepatan fluida yang dimasukkan dapat dipakai untuk menghitung flow rate fluida. Hasil penelitian ini menunjukkan bahwa simulasi perubahan diameter reservoir insulin akan mempengaruhi flow rate. Semakin kecil dimensi reservoir maka flow rate yang keluar dari nozzle mendekati flow rate yang telah diatur di program pompa infus insulin.
\end{abstract}

Kata kunci: Computational Fluid Mechanics, Velocity, Pressure, Peralatan Medis

\begin{abstract}
An insulin infusion pump is a semi-automatic medical device used to control blood glucose level of diabetic patient. The device works by infusing insulin from the insulin reservoir into the patient's body continuously. Insulin reservoir is a container where insulin is stored before being injected into the patient's body. The main components of insulin infusion pumps consist of a pump, a motor, a reservoir, tubes and a microprocessor. The device injects the insulin according to a regulated flow rate. The dimensions of the reservoir need to be considered so that the flow rate of the insulin is delivered accurately. The simulation of fluid velocity in the insulin reservoir was carried out using a computational fluid dynamics software. The entered fluid velocity were used to calculate fluid flow rates. The results of this study indicate that the simulation of changes in the diameter of the insulin reservoir will affect the flow rate. The smaller reservoir dimension make the flow rate that comes out of the nozzle approaches the flow rate that has been set in the insulin infusion pump program.
\end{abstract}

Keywords: Computational Fluid Mechanics, Velocity, Pressure, Medical Device

\section{Pendahuluan}

Pompa infus insulin adalah peralatan medis semiotomatis yang digunakan untuk mengontrol tingkat gula darah penderita diabetes. Cara kerja perangkat tersebut yaitu dengan cara memasukkan insulin dari reservoir insulin ke dalam tubuh pasien secara kontinu [1]. Reservoir insulin adalah tempat penyimpanan insulin sebelum dimasukkan ke dalam tubuh pasien. Komponen utama pompa infus insulin terdiri atas pompa, motor, 
reservoir, tube, dan microprocessor [2]. Pompa tersebut dapat diatur debitnya [3]. Selain itu, pompa tersebut masih memiliki kelemahan yakni aliran insulin yang masuk ke tubuh tidak stabil sehingga menyebabkan gula darah menjadi tidak teratur dan dapat meningkatkan risiko terjadinya hyperglycemia pada beberapa pasien [4]. Hyperglycemia sering terjadi pada pasien yang sakit kritis dan diabetes mellitus. Hyperglycemia perlu diwaspadai karena jika tidak terkontrol dapat menyebabkan komplikasi, seperti gangguan elektrolit dan risiko infeksi [5]. Beberapa laporan menyebutkan bahwa aliran yang tidak stabil dari sistem pompa infus mempengaruhi perubahan tekanan darah [6,7]. Efek yang ditimbulkan dari perubahan tekanan darah ini dapat menyebabkan pendarahan pada immature brain [8]. Oleh karena itu, nilai flow rate pada peralatan medis perlu diketahui. Salah satu faktor yang memengaruhi besarnya flow rate peralatan medis terletak pada dimensinya $[9,10]$. Penelitian ini bertujuan mendapatkan hubungan antara dimensi reservoir terhadap flow rate yang terjadi sehingga dapat digunakan sebagai acuan dalam membuat pompa infus insulin.

\section{Metode}

Perhitungan flow rate pada pompa infus insulin dimulai dengan proses pembuatan geometri reservoir dengan perangkat lunak Autodesk Inventor 2020. Skema geometri reservoir yang dibuat mengacu pada ISO 8537:2016. Contoh geometri yang dibuat ditampilkan pada Gambar 2.1 dan variasi diameter reservoir ditampilkan pada Tabel 2.1. Geometri tersebut kemudian di-import ke perangkat lunak yang berbasis computational fluid dynamics (CFD). Geometri tersebut diberi kecepatan fluida yang bekerja di infus insulin. Perangkat lunak yang digunakan untuk proses simulasi fluida pada geometri reservoir yaitu Autodesk Inventor Professional dan ANSYS.

$$
Q=A v\left(\frac{m^{3}}{g}\right)
$$

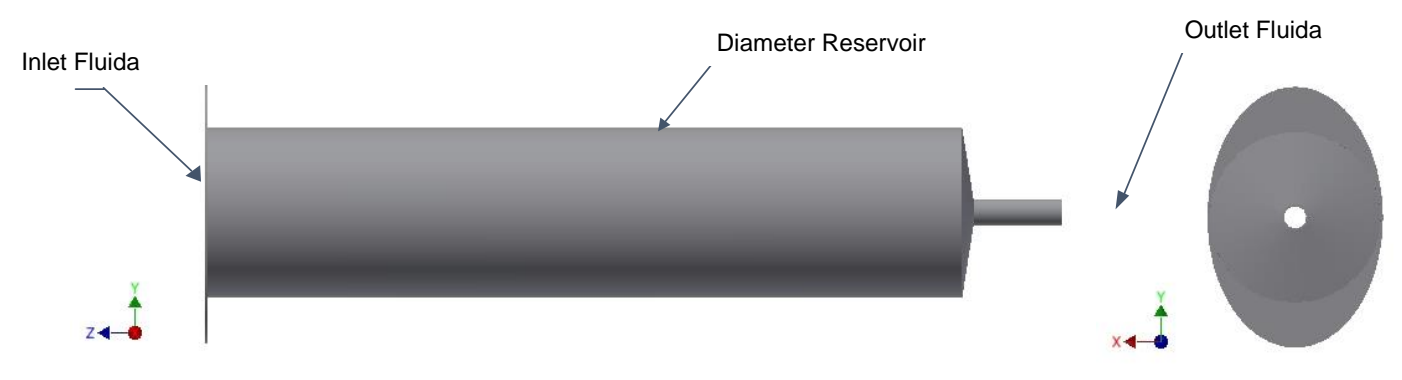

Gambar 2.1. Contoh geometri reservoir

Tabel 2.1. Variasi diameter reservoir

\begin{tabular}{cc}
\hline No. & $\begin{array}{c}\text { Variasi Diameter Reservoir } \\
(\mathbf{m m})\end{array}$ \\
\hline 1 & 14 \\
2 & 15 \\
3 & 16 \\
4 & 17 \\
5 & 18 \\
\hline
\end{tabular}

Material yang digunakan yaitu polypropylene. Pemakaian material polypropylene sebagai komponen infus insulin karena material tersebut sesuai dengan standar yang peralatan medis [11]. Kecepatan fluida di reservoir yang dimasukkan pada proses simulasi yaitu $2.91 \times 10^{-6} \mathrm{~m} / \mathrm{s}$. Kecepatan fluida tersebut didapatkan dari dosis insulin yang optimum untuk proses terapi [12]. Viskostas insulin diketahui sebesar $1.107 \mathrm{mPa}$ s [13]. Kecepatan digunakan untuk mendefinisikan flow rate yang terjadi. 


\section{Hasil dan Pembahasan}

Hasil simulasi pemberian kecepatan fluida pada sisi inlet geometri reservoir menggunakan perangkat lunak ANSYS menghasilkan kontur kecepatan dan kontur tekanan. Kecepatan fluida pada inlet berasal dari tekanan yang dihasilkan pompa infus insulin. Dimensi reservoir mempengaruhi kontur kecepatan dan kontur tekanan. Hal tersebut tersaji pada Gambar 3.1 dan Gambar 3.2.
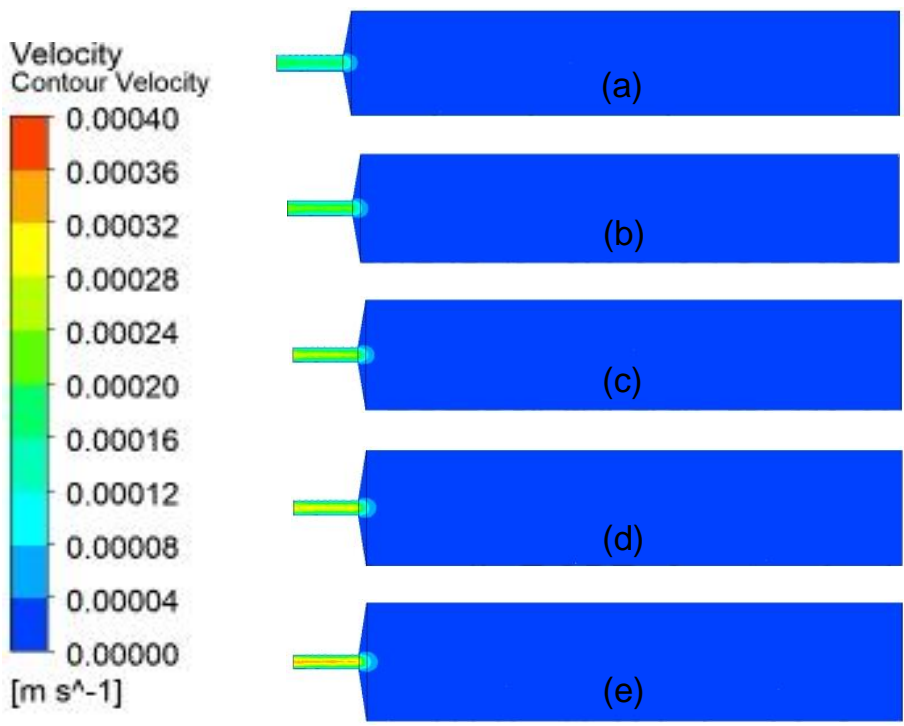

Gambar 3.1. Variasi flow rate hasil simulasi ANSYS 18.0 pada variasi diameter reservoir : (a) $14 \mathrm{~mm}$, (b) $15 \mathrm{~mm}$, (c) $16 \mathrm{~mm}$, (d) $17 \mathrm{~mm}$, (e) $18 \mathrm{~mm}$

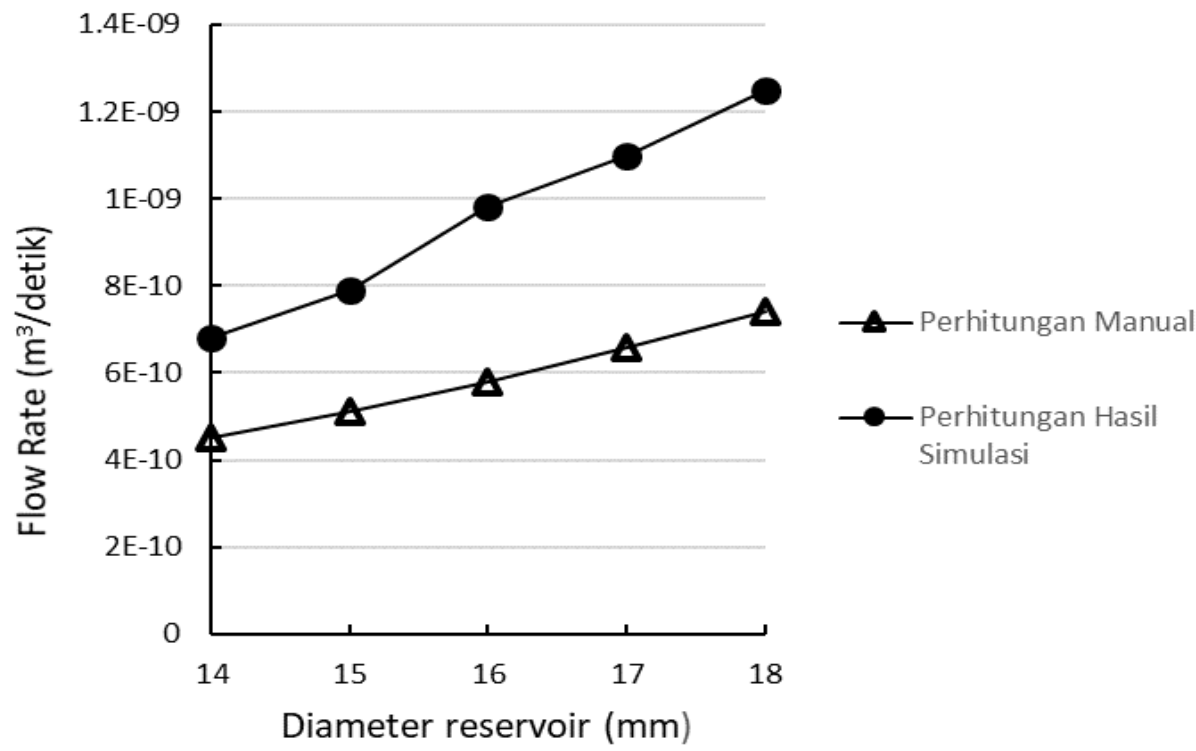

Gambar 3.2. Grafik hubungan antara variasi diameter reservoir dan flow rate

Hasil simulasi menggunakan perangkat lunak ANSYS menunjukkan semakin besar diameter reservoir, kecepatan fluida yang berada di outlet juga semakin besar. Hal tersebut ditampilkan di Gambar 3.1. Nilai kecepatan yang dihasilkan proses simulasi dengan perangkat lunak ANSYS dipakai untuk menghitung flow rate dengan memakai persamaan (1). Nilai flow rate hasil perhitungan dengan menggunakan variabel kecepatan yang dihitung 
dengan perbandingan luas inlet dan outlet ditampilkan di Tabel 3.1 dan flow rate yang dihasilkan dari perhitungan dengan memakai variabel kecepatan hasil simulasi ditampilkan di Tabel 3.2.

Tabel 3.1 dan Tabel 3.2 menunjukan bahwa dimensi inlet reservoir akan berpengaruh terhadap flow rate yang terjadi. Semakin besar luas penampang inlet, flow rate juga akan semakin besar. Kenaikan flow rate akan berpengaruh terhadap kecepatan fluida yang keluar.

Tabel 3.1. Data perhitungan manual flow rate

\begin{tabular}{ccccc}
\hline No. & $\begin{array}{c}\text { Diameter } \\
\text { Reservoir }(\mathbf{m m})\end{array}$ & $\begin{array}{c}\text { Diameter } \\
\text { outlet }(\mathbf{m m})\end{array}$ & $\begin{array}{c}\text { Kecepatan fluida } \\
\text { di outlet }(\mathbf{m} / \mathbf{s})\end{array}$ & $\begin{array}{c}\text { Flow rate } \\
\left(\mathbf{m}^{3} / \mathbf{s}\right)\end{array}$ \\
\hline 1 & 14 & 2,2 & $1,1 \times 10^{-4}$ & $4,5 \times 10^{-11}$ \\
\hline 2 & 15 & 2,2 & $1,3 \times 10^{-4}$ & $5,1 \times 10^{-11}$ \\
\hline 3 & 16 & 2,2 & $1,5 \times 10^{-4}$ & $5,8 \times 10^{-11}$ \\
\hline 4 & 17 & 2,2 & $1,7 \times 10^{-4}$ & $6,6 \times 10^{-11}$ \\
\hline 5 & 18 & 2,2 & $1,9 \times 10^{-4}$ & $7,4 \times 10^{-11}$ \\
\hline
\end{tabular}

Tabel 3.2. Data hasil simulasi menggunakan ANSYS

\begin{tabular}{ccccc}
\hline No. & $\begin{array}{c}\text { Diameter } \\
\text { Reservoir }(\mathbf{m m})\end{array}$ & $\begin{array}{c}\text { Diameter } \\
\text { outlet }(\mathbf{m m})\end{array}$ & $\begin{array}{c}\text { Kecepatan fluida } \\
\text { di outlet }(\mathbf{m} / \mathbf{s})\end{array}$ & $\begin{array}{c}\text { Flow rate } \\
\left(\mathbf{m}^{3} / \mathbf{s}\right)\end{array}$ \\
\hline 1 & 14 & 2,2 & $1,8 \times 10^{-4}$ & $6,8 \times 10^{-10}$ \\
\hline 2 & 15 & 2,2 & $2,1 \times 10^{-4}$ & $7,9 \times 10^{-10}$ \\
\hline 3 & 16 & 2,2 & $2,6 \times 10^{-4}$ & $9,8 \times 10^{-10}$ \\
\hline 4 & 17 & 2,2 & $2,9 \times 10^{-4}$ & $1,1 \times 10^{-9}$ \\
\hline 5 & 18 & 2,2 & $3,3 \times 10^{-4}$ & $1,25 \times 10^{-9}$ \\
\hline
\end{tabular}

Gambar 3.2 menunjukan bahwa diameter reservoir akan berpengaruh terhadap flow rate yang terjadi. Nilai flow rate antarvariasi hasil simulasi mempunyai interval yang lebih besar dibandingkan hasil perhitungan manual. Nilai flow rate yang terjadi tersebut dipengaruhi oleh kecepatan fluida yang terjadi pada outlet. Kecepatan fluida tersebut dipengaruhi oleh tekanan yang terjadi. Kontur tekanan yang terjadi pada setiap variasi tersaji pada Gambar 3.3. Kontur tekanan yang tersaji pada Gambar 3.3 menunjukan bahwa semakin besar diameter reservoir, area tekanan pada bagian pipa outlet akan semakin luas sehingga pengaruh pada kecepatan fluida keluar dari outlet lebih besar. Hubungan diameter, tekanan, dan kecepatan pada pompa infus insulin tersebut berlaku pada diameter $14 \mathrm{~mm}$ hingga $18 \mathrm{~mm}$.

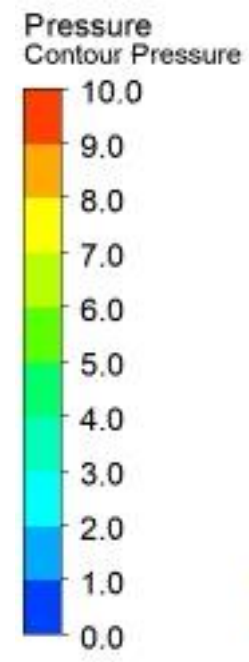

[Pa]
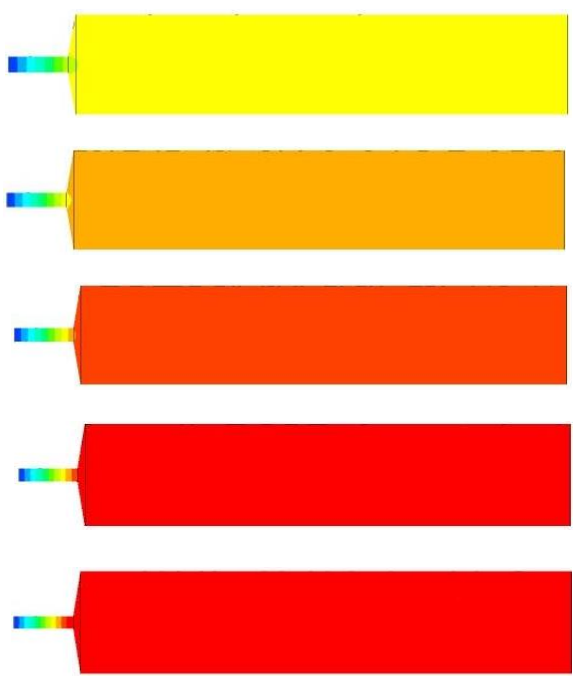

Gambar 3.3. Kontur tekanan hasil simulasi ANSYS 18.0 pada variasi diameter reservoir : (a) $14 \mathrm{~mm}$, (b) $15 \mathrm{~mm}$, (c) $16 \mathrm{~mm}$, (d) $17 \mathrm{~mm}$, (e) $18 \mathrm{~mm}$ 


\section{Kesimpulan}

Hasil perhitungan dan simulasi menunjukan bahwa diameter reservoir akan memengaruhi tekanan yang terjadi pada pompa infus insulin. Tekanan yang terjadi akan mempengaruhi kecepatan pada pipa outlet. Semakin besar nilai diameter reservoir akan mempengaruhi flow rate yang terjadi ketika kecepatan pada inlet dibuat sama. Kecepatan fluida tersebut dipengaruhi oleh tekanan yang terjadi. Kontur tekanan yang tersaji pada Gambar 4 menunjukan bahwa semakin besar diameter reservoir maka area tekanan pada bagian pipa outlet akan semakin luas sehingga pengaruh pada kecepatan fluida keluar dari outlet lebih besar. Hubungan diameter, tekanan, dan kecepatan pada pompa infus insulin tersebut berlaku pada diameter $14 \mathrm{~mm}$ sampai dengan $18 \mathrm{~mm}$.

\section{Daftar Pustaka}

[1] H. Xu and T. Maibaum, "An Event-B approach to timing issues applied to the generic insulion infusion pump," Int. Symp. Found. Heal. Informatics Eng. Syst., pp. 160-176, 2011.

[2] P. H. Schneider, W. J. Weber, and T. A. Massaro, "Insulin infusion pump," U.S. Patent No. $4,498,843,1985$.

[3] S. A. Klem, J. M. Farrington, and R. D. Leff "Influence of infusion pump operation and flow rate on hemodynamic stability during epinephrine insuion," Crit. Care Med., vol. 21, no. 8, pp. 1213-1217, 1993.

[4] S. W. Ponder, J. S. Skyler, D. F. Kruger, D. Matheson, and B. W. Brown, "Unexplained hyperglycemia in continuous subcutaneous insulin infusion: Evaluation and treatment," Diabetes Educ., vol. 34, no. 2, pp. 327-333, 2008.

[5] S. O. Butler, I. F. Btaiche, and C. Alaniz, "Relationship between hyperglycemia and infection in critically ill patients," Pharmacotherapy: The Journal of Human Pharmacology and Drug Therapy, vol. 25, no. 7, pp. 963-976, 2005.

[6] H. Shibata, M. Aibiki, Y. Shirakawa, and K. Ogli, "Dopamine infused continuously at high concentration with a low flow rate affects arterial blood pressure fluctuation waves," Crit. Care Med., vol. 21, no. 5, pp. 801-804, 1993.

[7] K. R. Dunster, P. B. Colditz, G. J. Joy, and Cunningham, "Cyclical variation of blood pressure and heart rate in neonates [1]," Arch. Dis. Child., vol. 70, no. 1 SUPPL., pp. 64-67, 1994.

[8] M. Funato H. Tamai, K. Noma, T. Kurita, Y. Kajimoto, Y. Yoshioka, and S. Shimada, "Clinical events in association with timing of intraventricular hemorrhage in preterm infants," J. Pediatr., vol. 121, no. 4, pp. 614-619, 1992.

[9] S. B. Genić, B. M. Jaćimović, and V. B. Genić, "Economic optimization of pipe diameter for complete turbulence," Energy Build., vol. 45, pp. 335-338, 2012.

[10] R. Kaji and B. J. Azzopardi, "The effect of pipe diameter on the structure of gas/liquid flow in vertical pipes," Int. J. Multiph. Flow, vol. 36, no. 4, pp. 303-313, 2010.

[11] N. Martakis, M. Niaounakis, and D. Pissimissis, "Gamma-sterilization effects and influence of the molecular weight distribution on the postirradiation resistance of polypropylene for medical devices," J. Appl. Polym. Sci., vol. 51, no. 2, pp. 313-328, 1994.

[12] W. Kidson, J. Casey, E. Kraegen, and L. Lazarus, "Treatment of severe diabetes mellitus by insulin infusion," Br. Med. J., vol. 2, no. 5921, pp. 691-694, 1974.

[13] G. G. Adams, A. Meal, P. S. Morgan, Q. E. Alzahrani, H. Zobel, R. Lithgo, M. S. Kok, D. T. M. Besong, S. I. Jiwani, S. Ballance, S. E. Harding, N. Chayen, and R. B. Gillis "Characterisation of insulin analogues therapeutically available to patients," PLoS One, vol. 13, no. 3, pp. 1-17, 2018. 